\title{
Evidence-based medicine (EBM) for undergraduate medical students in Sudan: sources of information, knowledge about terms, skills related to EBM and attitude toward EBM in Sudan
}

\author{
Elfatih A. Hasabo ${ }^{1 *}$, Walaa Elnaiem¹, Abrar Y. Ali ${ }^{1}$, Anfal M. Altahir ${ }^{1}$, Elmuiz A. Hsabo², Malaz I. Ibrahim,
} Dania M. Modathir ${ }^{1}$, Ryan T. Aljaaly ${ }^{3}$, Malaz M. ElSiddig ${ }^{4}$, Sara M. Abdalbagi ${ }^{5}$ and Heitham Awadalla ${ }^{6}$

\begin{abstract}
Background: Evidence-based medicine (EBM) is the use of the current best evidence for patient care. Medical students should critically appraise the research evidence to help them during their clinical practice in the future. We conducted this study to assess the skills, terms and attitude toward EBM.

Method: We conducted a cross-sectional study for medical students from governmental universities. Students completed an online validated questionnaire consisting of several sections to assess skills, attitude and knowledge about terms related to EBM. We used a scale ranging from 1(strongly disagree) to 5(strongly agree) for the 11 questions assessing the attitude and a scale ranging from 1(Poor) to 5(advanced) for EBM skills.

Results: A total of 761 medical students with a mean age of $21.97 \pm 1.64$ participated in the study. 327 (43\%) of them were males. The most commonly used search engines were Google 690 (91\%) and Wikipedia 465 (61\%). Medical books 719 (94\%) and lecture notes $353(46 \%)$ were the most common sources for health information. The majority of students rated their skills related to EBM as average and below average for all questions (overall $=2.18 \pm$ 0.8). Students rated their skills as poor (31\%) in locating professional literature, as average (34\%) in searching online databases, poor (42\%) in critical appraisal of a scientific publication reporting findings from clinical research and poor (36\%) in Critical appraisal of available scientific literature. Regarding attitude, the overall mean score was $2.83 \pm 0.76$. There is no significant difference in attitude score between students with or without EBM training $(P=$ $0.2)$.

The terms with the highest understanding were case-control study (45\%) and case report (44\%) for study design. Median (44\%) and sample size (43\%) for statistics. Incidence (46\%) and prevalence (44\%) for epidemiology.
\end{abstract}

\footnotetext{
* Correspondence: elfatih.ahmed.hasabo@gmail.com

${ }^{1}$ Faculty of Medicine, University of Khartoum, Khartoum, Sudan

Full list of author information is available at the end of the article
}

(c) The Author(s). 2021 Open Access This article is licensed under a Creative Commons Attribution 4.0 International License, which permits use, sharing, adaptation, distribution and reproduction in any medium or format, as long as you give appropriate credit to the original author(s) and the source, provide a link to the Creative Commons licence, and indicate if changes were made. The images or other third party material in this article are included in the article's Creative Commons licence, unless indicated otherwise in a credit line to the material. If material is not included in the article's Creative Commons licence and your intended use is not permitted by statutory regulation or exceeds the permitted use, you will need to obtain permission directly from the copyright holder. To view a copy of this licence, visit http://creativecommons.org/licenses/by/4.0/ The Creative Commons Public Domain Dedication waiver (http://creativecommons.org/publicdomain/zero/1.0/) applies to the data made available in this article, unless otherwise stated in a credit line to the data. 
Conclusions: Medical students have a knowledge gap in skills and terms related to EBM and an average attitude towards EBM. The majority of them were using a nonscientific search engine to obtain medical information. There is a need to educate students about the proper steps for getting the scientific literature and EBM skills.

Keywords: Evidence-based medicine, Sudan, Attitude, Source of information, Skills

\section{Background}

Researchers defined evidence-based medicine (EBM) as "conscientious, explicit, and judicious use of current best evidence in making decisions about the care of individual patients" [1]. EBM was focusing on how clinicians can use published literature. Thereafter, the concept was broadened to include the patient-doctor relationship in clinical practice, and integrating patient's preference with the physician's experience and the best available research evidence in the decision-making process [2]. Because of the importance of EBM in building clinical practice on a scientific basis, there is a focus on making the source of evidentiary based skills and information accessible to clinicians by developing reliable clinical practice guidelines [2]. EBM practice can be applied in five steps: step one; converting the current clinical scenario into an answerable question using PICOS mnemonic, step two; identifying the best available research evidence by performing a proper literature review across various databases, step three; critical appraisal of the evidence for its validity, impact, and applicability, step four; applying the results of the appraisal with the clinical experience and patient's values, and step five; evaluating the process and finding ways to improve it in the next time [3]. EBM has improved diagnosis, clinical judgment, and decision making [4]. Additionally, better outcomes were observed in patients who received evidence-based medical care [5]. EBM is of utmost importance in developing countries for its cost-effectiveness and efficient use of healthcare resources $[6,7]$.

Medical students are the future health care providers. Therefore, there is an increasing emphasis on exposing them to EBM during their pre-clinical and clinical education [8]. Nowadays, EBM has become a core part of the undergraduate medical education curriculum in many countries. Each step was discussed and the students were trained on translating the appraised evidence into clinical practice, this enhances student's critical thinking and life-long learning [9]. Among the Iranian medical students, only $24.5 \%$ were familiar with the concept of EBM [10]. In a Hungarian study [11]; students reported average skills in identifying patient's clinical questions, and finding and critically appraising the scientific literature, and poor skills in detecting the knowledge gaps. Less than $10 \%$ of the Hungarian students had advanced EBM skills [11]. Unfortunately, EBM is not adequately implemented in medical curricula for some developing countries [12], including Sudan where most of the medical students' curricula lack EBM tuition.

The practice of EBM among physicians in Sudan was found to be less than $56.3 \%$ [13]. Most of the Sudanese physicians have not received proper training in EBM [14]. Lack of skills was the main barrier In $57.6 \%$ of those physicians [13]. However, medical students' awareness, skills, and attitudes towards EBM practice in Sudan are still unknown. With a better understanding of the situation, educational and practical efforts can be developed to implement EBM into our health system. Therefore, this cross-sectional study is the first attempt to provide valuable evidence of medical students' awareness, skills, and attitudes towards proper EBM practice.

\section{Methods}

\section{Study design and settings}

This cross-sectional study was conducted among undergraduate medical students at ten public universities in Sudan where we included five public universities in Khartoum state and five universities outside Khartoum state in the study between November 2020 to January 2021.

In Khartoum state, the included governmental universities were: Alzaiem Alazhari university, Al-Neelain University, University of Khartoum, Omdurman Islamic university and University of Bahri. Outside Khartoum state. The other five universities were: University of El-imam El-Mahdi in White Nile state, University of Gezira in Gezira state, Red Sea University in Red Sea state, Nile Vally University in River Nile state and University of Kassala in Kassala state. We conducted this cross-sectional study following the STROBE statement for reporting cross-sectional studies [15].

\section{Participants}

We included all undergraduate medical students older than 18 years who were studying in their 2 nd year and above at the faculty of medicine in the selected public university. All undergraduate medical students who refused to participate were excluded from the study.

\section{Instruments used to measure the variables of interest in the study}

Data were collected from undergraduate medical students using this questionnaire (Additional file 1) that 
contained both open and close-ended questions. The questionnaire was distributed online to undergraduate medical students using google form.

The questionnaire consisted of 5 sections of questions: The first part: included 13 questions to assess sociodemographic data of the participating students, which were: age, gender, name of the university, year of study, marital status, attending a course in biostatistics, attending a course in evidence-based medicine, attending a course in research methodology, having a family member in healthcare, the frequency for reading scientific literature, having internet access and having free internet access at home or university. The second part included two questions to assess the most commonly used search engines and sources of information section (one question about the search engines used to obtain medical information and the other about the main sources of health information). The third part: included six questions to measure the skills in evidence-based medicine among undergraduate medical students and consist of a 5 -point Likert scale answers in 5 scales from poor $\{1\}$ to advanced $\{5\}$. The Scale was reproduced from Csertő1 et al. 2019 [11]. Cronbach's alpha in the original paper for the sub-scales was 0.85 . The fourth part: included eleven statements of questions to measure attitude toward using EBM in their future work as a health care professional among participating undergraduate medical students. Statements were evaluated by the students using 5 points Likert scales ranging from strongly disagree $\{1\}$ to strongly agree $\{5\}$. The Scale was reproduced from Csertö1 et al. 2019 [11]. Cronbach's alpha in the original paper for the sub-scales was 0.71 . The last part: To assess the knowledge of evidence-based medicine terms related to statistics, epidemiology and study design. Students evaluated their knowledge on a 5-point categorical scale. The five ratings were: $\{1\}$ I understand and I could explain to others; $\{2\}$ Some understanding; \{3\} I do not understand, but would like to understand; \{4\} I do not understand, but I think it wouldn't be helpful to me to understand; $\{5\}$ No idea about this. The Scale was reproduced from McColl et al. [16] and Nejašmić et al. [17].

\section{Data collection and Sampling}

Due to the COVID-19 pandemic, a convenience sampling method was used to acquire the responses from the participants via online distribution of google form during the study period. We recruited medical students from universities using an online google form. Investigators sent the online questionnaire to the online groups of included universities using social media such as Facebook and WhatsApp and telegram to undergraduate medical students. Weekly, Investigators were reminding undergraduate medical students during the study period in their online groups to participate to ensure broader participation in the study among undergraduate medical students.

\section{Sample size calculation}

The sample size for this study was calculated via The following equation $n=z^{2} P(1-P) / d^{2}[18]$. With a $95 \%$ Confidence Interval $(\mathrm{CI}), 50 \%$ response distribution and 0.05 margin of error, a sample of 384 participants can be considered as a minimal sample to represent the population.

\section{Statistical analysis}

We analyzed and described data using $\mathrm{R}$ software version 4.0.2. Continuous data were presented as mean \pm $\mathrm{SD}$, and categorical data were presented as numbers (percentage). We used the Kolmogorov-Smirnov test to check the normality of the data. To find a significant difference between groups, we used an independent t-test for normally distributed data and Mann-Whitney $U$ after rejecting the null hypothesis of the KolmogorovSmirnov test of normal distribution. We used the Chisquare test or Fisher exact test to find if there was a significant difference between the groups for categorical data. A P-value less than 0.05 is considered significant.

\section{Results}

\section{Participants' information}

761 Sudanese undergraduate medical students with a mean age of $21.97 \pm 1.64$ years participated in this crosssectional study. 327 (43.0\%) of total participants were males, and the most numbers of participants were from the second year $(23.3 \%)$ and the third year (31.7\%). One-fourth of participants $(26.15 \%)$ received or enrolled in training for evidence-based medicine. Regarding frequency for reading scientific literature, the majority of the students were either never read any scientific literature $193(25.4 \%)$ or read them monthly or less frequent 389 (51.1\%). Others baseline characteristics for the included medical students were shown in Table 1 .

\section{Search engine and sources of healthcare information retrieval}

Among the total medical students who participated in the study, students selected Google search 690 (90.7\%) and Wikipedia $465(61.1 \%)$ as the most common search engines among medical students. Nearly one third of total participant were using PubMed/Medline 245 (32.2\%) and Medscape 259 (34.0\%). Also, medical students who were enrolled in an EBM training were found to have a significant higher percentage for using PubMed/Medline (41.2\% vs. $29 \%$; $p=0.002)$, Medscape $(44.7 \%$ vs. $30.2 \% ; p<$ $0.001)$, Cochrane Library (11.1\% vs. $4.4 \% ; p=0.002)$ and Embase (3\% vs. $0.7 \%$; $p=0.024$ ). 
Table 1 Baseline characteristics of medical students who completed the online survey in Sudanese universities $(n=761)$

\begin{tabular}{|c|c|c|c|c|}
\hline \multirow[t]{2}{*}{ Variables } & \multirow{2}{*}{$\begin{array}{l}\text { Overall, } \\
N=761\end{array}$} & \multicolumn{2}{|l|}{ EBM Training } & \multirow[t]{2}{*}{$p$-value } \\
\hline & & Yes, $N=199$ & No, $N=562$ & \\
\hline Age (Years) & $21.97 \pm 1.64$ & $22.21 \pm 1.72$ & $21.89 \pm 1.60$ & 0.117 \\
\hline Gender & & & & 0.003 \\
\hline Female & $434(57.0 \%)$ & 95 (47.7\%) & $339(60.3 \%)$ & \\
\hline Male & $327(43.0 \%)$ & $104(52.3 \%)$ & $223(39.7 \%)$ & \\
\hline Marital status & & & & 0.019 \\
\hline Married & $22(2.9 \%)$ & $11(5.5 \%)$ & 11 (2.0\%) & \\
\hline Single & 739 (97.1 \%) & $188(94.5 \%)$ & $551(98.0 \%)$ & \\
\hline Year in university & & & & 0.004 \\
\hline Second & $177(23.3 \%)$ & $33(16.6 \%)$ & $144(25.6 \%)$ & \\
\hline Third & $241(31.7 \%)$ & 81 (40.7\%) & $160(28.5 \%)$ & \\
\hline Fourth & $166(21.8 \%)$ & 34 (17.1\%) & $132(23.5 \%)$ & \\
\hline Fifth & 127 (16.7\%) & 36 (18.1\%) & 91 (16.2\%) & \\
\hline Sixth & $50(6.6 \%)$ & $15(7.5 \%)$ & $35(6.2 \%)$ & \\
\hline Received or attended any physical or online course in biostatistics (yes) & $300(39.4 \%)$ & $124(62.3 \%)$ & $176(31.3 \%)$ & $<0.001$ \\
\hline Received or attended any physical or online course in Research methodology (Yes) & $382(50.2 \%)$ & $143(71.9 \%)$ & $239(42.5 \%)$ & $<0.001$ \\
\hline Family member (parent, sibling, spouse,.etc)working in health care (Yes) & $427(56.1 \%)$ & $122(61.3 \%)$ & $305(54.3 \%)$ & 0.1 \\
\hline Frequency of reading scientific literature: & & & & $<0.001$ \\
\hline Never & $193(25.4 \%)$ & $34(17.1 \%)$ & $159(28.3 \%)$ & \\
\hline Daily & $49(6.4 \%)$ & $20(10.1 \%)$ & $29(5.2 \%)$ & \\
\hline Weekly & $130(17.1 \%)$ & $48(24.1 \%)$ & $82(14.6 \%)$ & \\
\hline Monthly or less frequent & $389(51.1 \%)$ & $97(48.7 \%)$ & $292(52.0 \%)$ & \\
\hline Free internet access at your university or home (Yes) & $315(41.4 \%)$ & $84(42.2 \%)$ & $231(41.1 \%)$ & 0.9 \\
\hline Internet access (Yes) & $720(94.6 \%)$ & $190(95.5 \%)$ & $530(94.3 \%)$ & 0.7 \\
\hline \multicolumn{5}{|l|}{ Which of the following do you have: } \\
\hline Private computer or laptop & $454(59.7 \%)$ & $121(60.8 \%)$ & $333(59.3 \%)$ & 0.8 \\
\hline Tablet & $145(19.1 \%)$ & $36(18.1 \%)$ & $109(19.4 \%)$ & 0.8 \\
\hline Smart phone & $694(91.2 \%)$ & $177(88.9 \%)$ & $517(92.0 \%)$ & 0.2 \\
\hline
\end{tabular}

Data were presented as Mean \pm SD and number (percentage)

*Statistical tests performed: Independent T-test; chi-square test of independence; Fisher's exact test

Regarding the question "What do you see as the main source of health information? ", nearly all of them 719 (94.5\%) chose medical books as the main source of information, followed by lecture notes 353 (46.4\%). Students who received training in EBM were found selected professional guidelines more than students who didn't enrol in EBM training ( $45.2 \%$ vs $34.3 \% ; p=0.008$ ). More details about the search engines and sources for health information in Table 2.

\section{Self-reported skills in EBM}

The overall rating score of medical students for skills was $2.18 \pm 0.80$, which is considered a limited experience. The majority of students rating their skill as limited experience in locating professional literature $2.17 \pm$ 1.01 and Identifying patient-relevant clinical questions $2.39 \pm 1.07$, and the ability for medical students to search online databases was rated as average $2.59 \pm 1.11$. Also, the remaining skills were rated by students as poor for critical appraisal of scientific papers from clinical research $1.90 \pm 0.94$ or scientific literature $2.01 \pm 0.96$ and identifying knowledge gaps in practice $2.04 \pm 0.98$ (Table 3). Fewer students rated their skills as above average or advanced for EBM skills (Table 3).

Medical students who received or participated in EBM training rated all the items for EBM skills significantly higher than those who didn't receive the EBM course (Table 3).

\section{Attitudes of medical students towards using EBM in health care practice}

The overall attitude score for medical students was $2.83 \pm 0.76$. Although, the majority of them agreed that evidence-based medicine (EBM) is essential for the 
Table 2 Search engines and main sources of health information among Sudanese medical students $(n=761)$

\begin{tabular}{|c|c|c|c|c|}
\hline \multirow[t]{2}{*}{ Variables } & \multirow{2}{*}{$\begin{array}{l}\text { Overall, } \\
N=761\end{array}$} & \multicolumn{2}{|l|}{ EBM Training } & \multirow[t]{2}{*}{$p$-value } \\
\hline & & Yes, $N=199$ & No, $N=562$ & \\
\hline \multicolumn{5}{|l|}{ Search engines used: } \\
\hline Google & $690(90.7 \%)$ & 175 (87.9\%) & $515(91.6 \%)$ & 0.2 \\
\hline Google scholar & $243(31.9 \%)$ & 66 (33.2\%) & 177 (31.5\%) & 0.7 \\
\hline Wikipedia & $465(61.1 \%)$ & 119 (59.8\%) & $346(61.6 \%)$ & 0.7 \\
\hline PubMed/Medline & $245(32.2 \%)$ & $82(41.2 \%)$ & $163(29.0 \%)$ & 0.002 \\
\hline Medscape & $259(34.0 \%)$ & 89 (44.7\%) & $170(30.2 \%)$ & $<0.001$ \\
\hline Cochrane Library & $47(6.2 \%)$ & $22(11.1 \%)$ & $25(4.4 \%)$ & 0.002 \\
\hline Scopus & $13(1.7 \%)$ & $6(3.0 \%)$ & $7(1.2 \%)$ & 0.11 \\
\hline Web of science & $68(8.9 \%)$ & $18(9.0 \%)$ & $50(8.9 \%)$ & $>0.9$ \\
\hline Embase & $10(1.3 \%)$ & $6(3.0 \%)$ & $4(0.7 \%)$ & 0.024 \\
\hline Ovid & $2(0.3 \%)$ & $1(0.5 \%)$ & $1(0.2 \%)$ & 0.5 \\
\hline Others. & $31(4.1 \%)$ & $9(4.5 \%)$ & $22(3.9 \%)$ & 0.9 \\
\hline \multicolumn{5}{|c|}{ Main sources of health information: (You can choose multiple answers) } \\
\hline Medical books & $719(94.5 \%)$ & $187(94.0 \%)$ & $532(94.7 \%)$ & 0.9 \\
\hline Scientific journals & $313(41.1 \%)$ & $83(41.7 \%)$ & $230(40.9 \%)$ & $>0.9$ \\
\hline Electronic media & $271(35.6 \%)$ & $66(33.2 \%)$ & $205(36.5 \%)$ & 0.5 \\
\hline Professional guidelines & $283(37.2 \%)$ & $90(45.2 \%)$ & $193(34.3 \%)$ & 0.008 \\
\hline Leaflets & $43(5.7 \%)$ & $10(5.0 \%)$ & $33(5.9 \%)$ & 0.8 \\
\hline Lecture notes & $353(46.4 \%)$ & $92(46.2 \%)$ & $261(46.4 \%)$ & $>0.9$ \\
\hline Opinion of health professionals & $218(28.6 \%)$ & $57(28.6 \%)$ & $161(28.6 \%)$ & $>0.9$ \\
\hline Others & $5(0.7 \%)$ & $0(0.0 \%)$ & $5(0.9 \%)$ & 0.3 \\
\hline
\end{tabular}

Data were presented as Mean \pm SD and number (percentage)

* $S$ tatistical tests performed: Chi-square test of independence; Fisher's exact test

practical work of physicians $3.92 \pm 1.17$ (Table 4). But we didn't find any difference in the attitude score for the ten items of attitude out of 11 between medical students who received or didn't receive the EBM course (Table 4). The only significant difference in attitude score was found for the statement "Textbooks are the most optimal source of information, when a question regarding the care of patients should be answered" $(p=0.016)$, and it was higher for students who received EBM course (Table 4).

\section{Knowledge of terms related to EBM}

There was a massive difference in understanding EBM terms. The most known and understandable term related to study design terms was case-control study 342 (44.9\%), followed by case report 335 (44.0\%).

Table 3 Responses on a 5-point scale to the question: "How would you rate your skills in the following areas?" among Sudanese medical students $(n=761)$

\begin{tabular}{|c|c|c|c|c|c|c|c|c|}
\hline $\begin{array}{l}\text { How would you rate your skills in the } \\
\text { following areas? }\end{array}$ & Poor & $\begin{array}{l}\text { Limited } \\
\text { experience }\end{array}$ & Average & $\begin{array}{l}\text { Above } \\
\text { Average }\end{array}$ & Advanced & $\begin{array}{l}\text { Students with } \\
\text { EBM training }\end{array}$ & $\begin{array}{l}\text { Students without } \\
\text { EBM training }\end{array}$ & $P$ - Value ${ }^{*}$ \\
\hline Locating professional literature. & $234(30.7 \%)$ & $251(33.0 \%)$ & $197(25.9 \%)$ & $68(8.9 \%)$ & $11(1.4 \%)$ & $2.34 \pm 1.01$ & $2.11 \pm 1.01$ & 0.004 \\
\hline Searching online databases. & $154(20.2 \%)$ & $192(25.2 \%)$ & $258(33.9 \%)$ & $123(16.2 \%)$ & $34(4.5 \%)$ & $2.76 \pm 1.06$ & $2.53 \pm 1.13$ & 0.006 \\
\hline $\begin{array}{l}\text { Critical appraisal of a scientific publication } \\
\text { reporting findings from clinical research. }\end{array}$ & $319(41.9 \%)$ & $253(33.2 \%)$ & $147(19.3 \%)$ & $32(4.2 \%)$ & $10(1.3 \%)$ & $2.03 \pm 0.98$ & $1.85 \pm 0.93$ & 0.025 \\
\hline $\begin{array}{l}\text { Identifying knowledge gaps in practice } \\
\text { (fields where not enough scientific literature is } \\
\text { available to answer specific clinical question). }\end{array}$ & $271(35.6 \%)$ & 255 (33.5 \%) & 176 (23.1\%) & $49(6.4 \%)$ & $10(1.3 \%)$ & $2.23 \pm 1.00$ & $1.98 \pm 0.97$ & 0.002 \\
\hline Critical appraisal of available scientific literature. & $273(35.9 \%)$ & $265(34.8 \%)$ & $173(22.7 \%)$ & $39(5.1 \%)$ & $11(1.4 \%)$ & $2.20 \pm 0.97$ & $1.95 \pm 0.95$ & $<0.001$ \\
\hline Identifying patient-relevant clinical questions. & $178(23.4 \%)$ & $254(33.4 \%)$ & $210(27.6 \%)$ & $96(12.6 \%)$ & $23(3.0 \%)$ & $2.56 \pm 1.03$ & $2.32 \pm 1.07$ & 0.004 \\
\hline Overall score & & & & & & $2.35 \pm 0.79$ & $2.12 \pm 0.80$ & $<0.001$ \\
\hline
\end{tabular}

Data were presented as Mean \pm SD and number (percentage)

*Statistical tests performed: Mann-Whitney $U$ test 


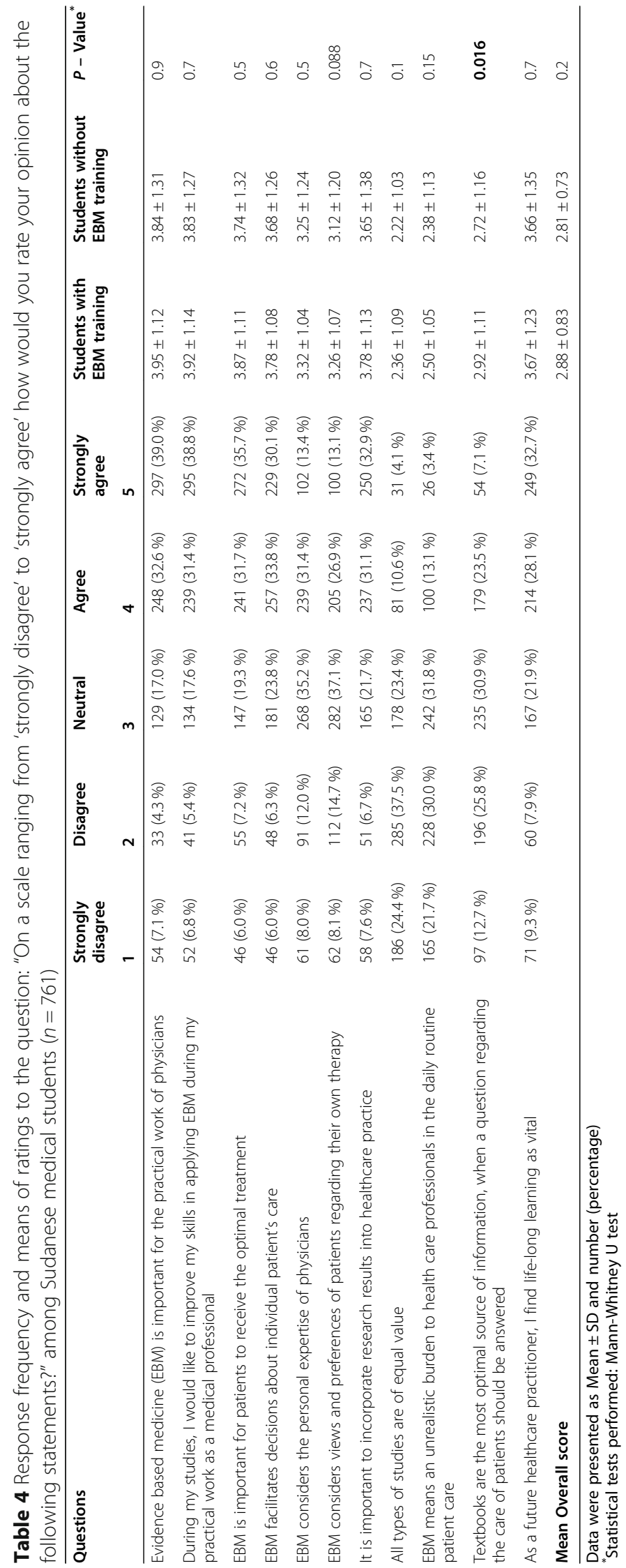


Table. 5 Self-reported understanding of evidence-based healthcare-related terms among Sudanese medical students ( $n=761$ )

\begin{tabular}{|c|c|c|c|c|c|}
\hline & $\begin{array}{l}\text { I understand and } \\
\text { I could explain to } \\
\text { others. }\end{array}$ & Some understanding. & $\begin{array}{l}\text { Do not understand, } \\
\text { but would like to } \\
\text { understand. }\end{array}$ & $\begin{array}{l}\text { Do not understand, } \\
\text { but I think, it wouldn't } \\
\text { be helpful to me to } \\
\text { understand }\end{array}$ & $\begin{array}{l}\text { No idea } \\
\text { about this }\end{array}$ \\
\hline \multicolumn{6}{|l|}{ Terms related to study design: } \\
\hline Case report & $335(44.0 \%)$ & $279(36.7 \%)$ & $110(14.5 \%)$ & $11(1.4 \%)$ & $26(3.4 \%)$ \\
\hline Cohort study & $286(37.6 \%)$ & $278(36.5 \%)$ & $135(17.7 \%)$ & $13(1.7 \%)$ & $49(6.4 \%)$ \\
\hline $\begin{array}{l}\text { Randomized Controlled } \\
\text { clinical trial }\end{array}$ & $202(26.5 \%)$ & $276(36.3 \%)$ & $203(26.7 \%)$ & $24(3.2 \%)$ & $56(7.4 \%)$ \\
\hline Meta-analysis & $115(15.1 \%)$ & $275(36.1 \%)$ & $277(36.4 \%)$ & $28(3.7 \%)$ & $66(8.7 \%)$ \\
\hline Systematic review & $200(26.3 \%)$ & $280(36.8 \%)$ & $212(27.9 \%)$ & 19 (2.5\%) & $50(6.6 \%)$ \\
\hline Cross-sectional study & $315(41.4 \%)$ & $244(32.1 \%)$ & $153(20.1 \%)$ & $16(2.1 \%)$ & $33(4.3 \%)$ \\
\hline Case-control study & $342(44.9 \%)$ & $235(30.9 \%)$ & $139(18.3 \%)$ & $14(1.8 \%)$ & $31(4.1 \%)$ \\
\hline \multicolumn{6}{|l|}{ Terms related to statistics: } \\
\hline Confidence interval & $146(19.2 \%)$ & $284(37.3 \%)$ & $236(31.0 \%)$ & $20(2.6 \%)$ & $75(9.9 \%)$ \\
\hline Sample size & $330(43.4 \%)$ & $250(32.9 \%)$ & $122(16.0 \%)$ & $17(2.2 \%)$ & $42(5.5 \%)$ \\
\hline Mode & $292(38.4 \%)$ & $212(27.9 \%)$ & $176(23.1 \%)$ & $18(2.4 \%)$ & $63(8.3 \%)$ \\
\hline Median & $334(43.9 \%)$ & $203(26.7 \%)$ & $155(20.4 \%)$ & $13(1.7 \%)$ & $56(7.4 \%)$ \\
\hline Interquartile range (IQR) & $146(19.2 \%)$ & $239(31.4 \%)$ & $263(34.6 \%)$ & $31(4.1 \%)$ & $82(10.8 \%)$ \\
\hline Standard deviation (SD) & $248(32.6 \%)$ & $250(32.9 \%)$ & $174(22.9 \%)$ & $28(3.7 \%)$ & $61(8.0 \%)$ \\
\hline Precision and accuracy & $145(19.1 \%)$ & $245(32.2 \%)$ & $269(35.3 \%)$ & $27(3.5 \%)$ & $75(9.9 \%)$ \\
\hline Representative sample & $213(28.0 \%)$ & $260(34.2 \%)$ & $201(26.4 \%)$ & $23(3.0 \%)$ & $64(8.4 \%)$ \\
\hline Test power & $103(13.5 \%)$ & $233(30.6 \%)$ & $305(40.1 \%)$ & $29(3.8 \%)$ & $91(12.0 \%)$ \\
\hline$P$-value & $146(19.2 \%)$ & $252(33.1 \%)$ & $241(31.7 \%)$ & $32(4.2 \%)$ & $90(11.8 \%)$ \\
\hline Type I and type II errors & $114(15.0 \%)$ & $247(32.5 \%)$ & $281(36.9 \%)$ & $26(3.4 \%)$ & $93(12.2 \%)$ \\
\hline \multicolumn{6}{|l|}{ Terms related to Epidemiology: } \\
\hline Relative risk & $248(32.6 \%)$ & $275(36.1 \%)$ & $170(22.3 \%)$ & $15(2.0 \%)$ & $53(7.0 \%)$ \\
\hline Absolute risk & $223(29.3 \%)$ & $273(35.9 \%)$ & $197(25.9 \%)$ & $19(2.5 \%)$ & $49(6.4 \%)$ \\
\hline Odds ratio & $175(23.0 \%)$ & $269(35.3 \%)$ & $227(29.8 \%)$ & $22(2.9 \%)$ & $68(8.9 \%)$ \\
\hline NNT (number needed to treat) & $118(15.5 \%)$ & $223(29.3 \%)$ & $302(39.7 \%)$ & $23(3.0 \%)$ & $95(12.5 \%)$ \\
\hline Sensitivity of a diagnostic test & $238(31.3 \%)$ & $233(30.6 \%)$ & $213(28.0 \%)$ & $23(3.0 \%)$ & $54(7.1 \%)$ \\
\hline Specificity of a diagnostic test & $232(30.5 \%)$ & $235(30.9 \%)$ & $221(29.0 \%)$ & $18(2.4 \%)$ & $55(7.2 \%)$ \\
\hline Heterogeneity & $138(18.1 \%)$ & $213(28.0 \%)$ & $296(38.9 \%)$ & $34(4.5 \%)$ & $80(10.5 \%)$ \\
\hline Publication bias & $146(19.2 \%)$ & $227(29.8 \%)$ & $276(36.3 \%)$ & $26(3.4 \%)$ & $86(11.3 \%)$ \\
\hline Lost to follow-up & $187(24.6 \%)$ & $238(31.3 \%)$ & $224(29.4 \%)$ & $29(3.8 \%)$ & $83(10.9 \%)$ \\
\hline Randomization & $270(35.5 \%)$ & 247 (32.5\%) & $164(21.6 \%)$ & $21(2.8 \%)$ & $59(7.8 \%)$ \\
\hline Intention-to-treat analysis & $115(15.1 \%)$ & $211(27.7 \%)$ & $310(40.7 \%)$ & $24(3.2 \%)$ & $101(13.3 \%)$ \\
\hline Prevalence & $332(43.6 \%)$ & $241(31.7 \%)$ & $123(16.2 \%)$ & $20(2.6 \%)$ & $45(5.9 \%)$ \\
\hline Incidence & $347(45.6 \%)$ & $232(30.5 \%)$ & $118(15.5 \%)$ & $23(3.0 \%)$ & $41(5.4 \%)$ \\
\hline Positive predictive value & $163(21.4 \%)$ & $231(30.4 \%)$ & $260(34.2 \%)$ & $28(3.7 \%)$ & 79 (10.4\%) \\
\hline Hierarchy of evidence & $117(15.4 \%)$ & $200(26.3 \%)$ & $315(41.4 \%)$ & $28(3.7 \%)$ & $101(13.3 \%)$ \\
\hline Clinical effectiveness & $146(19.2 \%)$ & $246(32.3 \%)$ & $274(36.0 \%)$ & $27(3.5 \%)$ & $68(8.9 \%)$ \\
\hline Practical guideline & $160(21.0 \%)$ & $258(33.9 \%)$ & $255(33.5 \%)$ & $21(2.8 \%)$ & $67(8.8 \%)$ \\
\hline Evidence-based medicine & $230(30.2 \%)$ & 279 (36.7\%) & $186(24.4 \%)$ & $23(3.0 \%)$ & $43(5.7 \%)$ \\
\hline
\end{tabular}


Unfortunately, meta-analysis 115 (15.1\%) and systematic review $200(26.3 \%)$ were the least known terms related to study design (Table 5).

Regarding terms related to statistics, most of the students showed less understanding for this domain, and median 334 (43.9\%) and sample size 330 (43.4\%) were the most known understandable term (Table 5).

Regarding terms related to epidemiology, students identified incidence 347 (45.6\%) and prevalence 332 $(43.6 \%)$ as the most known terms for them, and intention-to-treat analysis $115(15.1 \%)$ as the least known term (Table 5).

\section{Discussion}

This cross-sectional study was designed to map the attitudes, knowledge and skills related to EBM among medical students in Sudan. The attitude towards EBM was generally positive, a finding that was demonstrated in other studies as well $[17,19-24]$. However, our study revealed that lacking prior training in EBM did not result in an inferior perception of EBM as one might expect. In fact, the only difference observed between the two groups regarding the attitude towards EBM was the gravitation towards textbooks as key source of information guiding patient care. We noticed that students with EBM training were more likely to consult a textbook when attempting to answer a clinical question. Furthermore, the majority of the students were neutral regarding the statement 'EBM considers views and preferences of patients regarding their own therapy'.

On analyzing the students' responses to the questions assessing the level of understanding of EBM-related terms, we noticed considerable differences in their comprehension of the various EBM-related terms. The majority of students felt confident with their knowledge of the concept of case report (80.7\%), meta-analysis seemed to be the weakest area among the terms related to study design (51.2\%). Regarding the statistical terms, we found that the 'sample size' was the most understood term $(76.3 \%)$, followed by the 'median' (70.6\%). Almost half of the students could not explain the advanced terms like Type I and type II errors, 'test power', and interquartile range. This finding could be partly explained by the fact that most of the participating universities start teaching their students advanced statistical and epidemiological topics earlier during their study.

Generally, most of the students involved in the study declared having limited experience in the skills pertaining to applying EBM. This is particularly true when it comes to the ability to critique a scientific publication where the two groups saw the worst performance on average. As expected, students with EBM training scored higher than their counterparts who did not receive any training. It is also worth mentioning that EBM-trained students reported significantly better skills in locating professional literature, searching online databases, critiquing a scientific paper, identifying knowledge gap in practice and pinpointing patient-specific clinical questions. Unfortunately, most of the Sudanese medical students had less EBM skills than Hungarian medical students who show an average EBM skill [11].

Two similar studies were identified from the literature: a survey with 1080 participants in Hungary [11] and a cross-sectional study conducted in Iran [10]. Across all studies, there was generally a positive attitude toward EBM. Similarly, both studies demonstrated limited formal training in EBM among students, low utilization of the advanced online EBM resources (like Cochrane) and poor familiarity with the various EBM-related terms. The data from F. Ghahremanfard et al. [10] suggested that students depend on textbooks and expert opinions when seeking clinical information. This is different from our study, which showed that medical journals and lecture notes were the major sources of information. Csertö $\mathrm{M}$, et al. [11] concluded that students who had received training in EBM tended to be significantly better at critical appraisal and knowledge gaps identification, which is similar to our finding.

We identified another questionnaire-based survey [25] performed among medical students at the Faculty of Medicine, University of Damascus (Syria) where 50 students were given an EBM course and an identical set of test questionnaires were distributed before and after completing the course. Unlike our study, the percentage of students who had received EBM training beforehand was noticeably higher in their study (56\% vs. $26.15 \%$ ). That is being said, a lot of similarities had risen upon comparing our results with their baseline (pre-course) findings. For instance, it appears that the majority of the students had conducted an online search for literature infrequently (< once per week) (68\% vs. $76.5 \%$ ), with almost half of the students found it difficult to search for the literature online ( $47.9 \%$ vs. $45.4 \%)$ and only limited number of them felt competent at critically appraising a scientific paper (34\% vs. $24.8 \%$ ). Moreover, Google was the most used search engine to search the literature in both studies (46\% vs. $90.7 \%$ ), a finding that can be explained -in part- by the lack of institutional access to subscription journals. When it comes to the attitudes toward EBM, the vast majority of students were keen to receive professional training in EBM (98\% vs. $87.8 \%$ ).

Regarding terms related to EBM, Incidence rate (37.8\%) and Publication bias $(21.7 \%)$ were found to be the most common understandable terms among Iranian medical students [10]. In another study, sample size (65.09\%) and case study (59.07\%) were the most common understandable terms among Hungarian students [11]. These findings are different from our study, which 
identified incidence (45.6\%) and case-control study $(44.9 \%)$ as the most understandable terms among $\mathrm{Su}$ danese medical students. On the other hand, other studies showed a low awareness of extracting journals, review publications, and databases relevant to evidencebased medicine among general practitioners [19-21, 23].

Previously, tools such as Fresno tool [26] and assessing competency in EBM (ACE) tool [27] were used to evaluate EBM steps and skills. The ACE tool consists of 15 items that assess the 5- steps of EBM which was validated among medical trainees [27], and the Fresno tool for assessing EBM skills [26]. Fresno tool consists of 12 items and it was validated and used in a previous study among pharmacy students [28]. Both tools assess the ability to apply steps of EBM and skills by giving an example and this is different from our study.

As far as we know, this is the first study that compared attitudes, knowledge and skills between Sudanese medical students who participated in an EBM training course and those who did not. One of the strength points of our study is the large sample size and multiple included universities, which could dampen the impact of response bias on the study findings. Because of this broad coverage, the results of this study are likely to be generalizable to the Sudanese medical students, and this study can serve as a starting point for future studies in countries with similar characteristics. Our results also highlight the importance of establishing focused, unified courses in EBM across all Sudanese universities and reiterating the need to apply EBM to individual patient care.

Despite the strength of our study, we encountered several limitations. Firstly, the responses recorded in the survey are self-reported and hence subjective. Therefore, they may not reflect the actual knowledge and the ability of an individual to apply EBM into their practice. Moreover, we did not ascertain the level of EBM training an individual had received; the exact number of hours engaged or the type of session delivered -whether face-toface or online-. Lastly, our study sample might not have been representative of all Sudanese medical students, mainly because of COVID-19 pandemic in addition to financial difficulties that restricted some students' access to the internet. Therefore, some students were not able to participate in the study.

\section{Conclusions}

Medical students have a knowledge gap in skills and terms related to EBM and an average attitude towards using EBM in health care practice. The majority were using a nonscientific search engine to obtain medical information due to the lack of institutional access in universities. They get medical information from medical books and lecture notes. There is a need to educate students about the proper steps for obtaining scientific literature.

To fill this gap in EBM among medical students, further interventional studies and training in EBM are required to improve EBM knowledge among medical students. Also, University staff should focus on secondary research such as systematic review and metaanalysis; because most of the participants don't know them. To apply this knowledge, practical sessions for improving the skills of EBM should be included in the curriculum to enhance their skills. Lastly, the Ministry of higher education and universities should inform medical students about the importance of EBM and establish scientific meetings to motivate students to be involved in research and increase their knowledge about EBM.

\section{Supplementary Information}

The online version contains supplementary material available at https://doi. org/10.1186/s12909-021-02902-6.

\section{Additional file 1}

\section{Acknowledgements}

We would like to thank Ghassan E. Ahmed, Sara Emad, Mai D. Mahmoud and Raed M. Alkhalifa for their help in collecting the data. Also, we would like to thank medical students for their participation in our study.

\section{Authors' contributions \\ EA. Hasabo, WE, AYA, AMA: idea conception, study design. EA. Hasabo, EA. Hsabo: Questionnaire design. WE, AYA, MII, DMM, RTA, MMS, SAM: Data collection and data creation. EA. Hasabo: Analysis planning, data analysis and interpretation. EA. Hasabo, WE, MII, DMM, AMA, EA. Hsabo: Manuscript drafting. HA: Study design and Supervision. All authors revised the manuscript and approved it for publication. \\ Funding \\ This study received no funding. \\ Availability of data and materials \\ The datasets used and/or analyzed during the current study are available from the corresponding author on reasonable request.}

\section{Declarations}

Ethics approval and consent to participate

Ethical approval of the study was obtained from the IRB committee in the faculty of medicine, University of Khartoum, Khartoum, Sudan. The study was carried out following the relevant ethical guidelines and regulations. The participants were asked to give consent that they agree to participate in the study by filling the questionnaire for research purposes in the online form, and all the participants provided informed consent.

Consent for publication

No personal data was collected from the participants.

Competing interests

The authors declare that they have no competing interests.

\section{Author details}

${ }^{1}$ Faculty of Medicine, University of Khartoum, Khartoum, Sudan. ${ }^{2}$ Department of Urology, Wythenshawe hospital, Manchester University NHS Foundation Trust, Manchester, United Kingdom. ${ }^{3}$ Faculty of Medicine, Nile Valley University, Atbara, Sudan. ${ }^{4}$ Faculty of Medicine, University of Gezira, Gezira, Sudan. ${ }^{5}$ Faculty of Medicine, University of Kassala, Kassala, Sudan. 
${ }^{6}$ Department of Community Medicine, Faculty of Medicine, University of Khartoum, Khartoum, Sudan.

Received: 29 May 2021 Accepted: 22 August 2021

Published online: 04 September 2021

\section{References}

1. Freddi G, Romàn-Pumar JL. Evidence-based medicine: what it can and cannot do. Ann Ist Super Sanita [Internet]. 2011;47(1):22-5. Available from: http://www.ncbi.nlm.nih.gov/pubmed/21430334

2. Djulbegovic B, Guyatt GH. Progress in evidence-based medicine: a quarter century on. Lancet [Internet]. 2017 Jul;390(10092):415-23. Available from: https:/linkinghub.elsevier.com/retrieve/pii/S0140673616315926

3. Sackett DL, Rosenberg WM. The need for evidence-based medicine. J R Soc Med [Internet]. 1995 Nov:88(11):620-4. Available from: http://www.ncbi.nlm. nih.gov/pubmed/8544145

4. Bradt P, Moyer V. How to teach evidence-based medicine. Clin Perinatol [Internet]. 2003 Jun;30(2):419-33. Available from: https://linkinghub.elsevier. com/retrieve/pii/S0095510803000198

5. Shortell SM, Rundall TG, Hsu J. Improving Patient Care by Linking EvidenceBased Medicine and Evidence-Based Management. JAMA [Internet]. 2007 Aug 8;298(6):673. Available from: http://jama.jamanetwork.com/article.a spx?doi=10.1001/jama.298.6.673

6. Misra UK. Barriers to evidence based medicine practice in South Asia and possible solutions. Neurol Asia. 2008;87-94.

7. Grol R, Grimshaw J. From best evidence to best practice: effective implementation of change in patients' care. Lancet [Internet]. 2003 Oct; 362(9391):1225-30. Available from: https://inkinghub.elsevier.com/retrieve/ pii/S0140673603145461

8. Health Professions Education [Internet]. Vol. 5. Washington, D.C.: National Academies Press; 2003. 207-212 p. Available from: http://www.nap.edu/cata $\log / 10681$

9. Greenhalgh T. " Is my practice evidence-based ?" Should be answered in qualitative, as well as quantitative terms. 2013;(December):10-2.

10. Ghahremanfard F, Nassaji M, Mirmohammadkhani M, Tanha A, Mosavi M, Ghaemi A, et al. Knowledge and attitude toward evidence-based medicine among medical students in Semnan, Iran. J Evid Based Med [Internet]. 2014 Feb;7(1):32-7. Available from: https://doi.org/10.1111/jebm.12084

11. Csertő M, Berényi K, Decsi T, Lohner S. Self-reported attitudes, knowledge and skills of using evidence-based medicine in daily health care practice: A national survey among students of medicine and health sciences in Hungary. Bianchi C, editor. PLoS One [Internet]. 2019 Dec 27;14(12): e0225641. Available from: https://doi.org/10.1371/journal.pone.0225641

12. Zwolsman SE, Dijk N Van, Verhoeven AAH, Ruijter W De, Waard MW. How learning style affects evidence-based medicine: a survey study. BMC Med Educ. 2011;11(1):81.

13. Ahmed H, Mohamed E, Abdalla S, Madani K, Kaliyadan F. Knowledge, attitude and practices of evidence-based medicine among Sudanese medical doctors. Educ Heal [Internet]. 2015;28(2):152. Available from: http:// www.educationforhealth.net/text.asp?2015/28/2/152/170128

14. Jones S, Wdc M, Gao W, Ij H, Wilcock A, Maddocks M. Neuromuscular electrical stimulation for muscle weakness in adults with advanced disease (Review). 2016;(10).

15. von Elm E, Altman DG, Egger M, Pocock SJ, Gøtzsche PC, Vandenbroucke JP. The Strengthening the Reporting of Observational Studies in Epidemiology (STROBE) Statement: Guidelines for Reporting Observational Studies. PLoS Med [Internet]. 2007 Oct 16;4(10):e296. Available from: https:// doi.org/10.1371/journal.pmed.0040296

16. McColl A, Smith H, White P. Field J. General practitioners' perceptions of the route to evidence based medicine: a questionnaire survey. BMJ [Internet]. 1998 Jan 31;316(7128):361-5. Available from: https://www.bmj.com/lookup/ doi/https://doi.org/10.1136/bmj.316.7128.361

17. Nejašmić D, Vrdoljak D, Bralić Lang V, Borovac JA, Marušić A. Awareness, attitudes, barriers, and knowledge about evidence-based medicine among family physicians in Croatia: a cross-sectional study. BMC Fam Pract [Internet]. 2020 Dec 16;21(1):88. Available from: https://bmcfampract. biomedcentral.com/articles/https://doi.org/10.1186/s12875-020-01162-5

18. Pourhoseingholi MA, Vahedi M, Rahimzadeh M. Sample size calculation in medical studies. Gastroenterol Hepatol from Bed to Bench. 2013;6(1):14-7.

19. Risahmawati RR, Emura SS, Nishi TT, Koizumi SS. Japanese Resident Physicians' Attitudes, knowledge, and Perceived Barriers on the Practice of
Evidence Based Medicine: a Survey. BMC Res Notes [Internet]. 2011 Dec 28; 4(1):374. Available from: https://bmcresnotes.biomedcentral.com/articles/ https://doi.org/10.1186/1756-0500-4-374

20. Kljakovic M. Practising GPs teaching medical students evidence based medicine-a questionnaire survey. Aust Fam Physician [Internet]. 2006 Dec; 35(12):999-1002. Available from: http://www.ncbi.nlm.nih.gov/pubmed/1714 9476

21. McAlister FA, Graham I, Karr GW, Laupacis A. Evidence-based medicine and the practicing clinician. J Gen Intern Med [Internet]. 1999 Apr;14(4):236-42. Available from: http://link.springer.com/https://doi.org/10.1046/j.1525-1497.1 999.00323.x

22. Al-Baghlie N, Al-Almaie SM. Physician attitudes towards evidence-based medicine in eastern Saudi Arabia. Ann Saudi Med [Internet]. 2004 Nov;24(6): 425-8. Available from: http://www.annsaudimed.net/doi/https://doi.org/10. 5144/0256-4947.2004.425

23. Albarqouni L, Elessi K. Awareness, attitudes and knowledge about evidencebased medicine among doctors in Gaza: a crosssectional survey. East Mediterr Health J [Internet]. 2017 Nov 19;23(9):626-31. Available from: http://www.ncbi.nlm.nih.gov/pubmed/29178120

24. Hong J, Chen J. Clinical Physicians' Attitudes towards Evidence-Based Medicine (EBM) and Their Evidence-Based Practice (EBP) in Wuhan, China. Int J Environ Res Public Health [Internet]. 2019 Oct 7:16(19):3758. Available from: https://www.mdpi.com/

25. Alahdab F, Firwana B, Hasan R, Sonbol MB, Fares M, Alnahhas I, et al. Undergraduate medical students' perceptions, attitudes, and competencies in evidence-based medicine (EBM), and their understanding of EBM reality in Syria. BMC Res Notes [Internet]. 2012 Dec 12;5(1):431. Available from: https://bmcresnotes.biomedcentral.com/articles/10.1186/1756-0500-5-431

26. Ramos KD, Schafer S, Tracz SM. Validation of the Fresno test of competence in evidence based medicine. BMJ [Internet]. 2003 Feb 8;326(7384):319-21. Available from: http://www.ncbi.nlm.nih.gov/pubmed/12574047

27. Ilic D, Nordin R Bin, Glasziou P, Tilson JK, Villanueva E. Development and validation of the ACE tool: assessing medical trainees' competency in evidence based medicine. BMC Med Educ [Internet]. 2014 Dec 9;14(1):114. Available from: https://bmcmededuc.biomedcentral.com/articles/10.1186/14 72-6920-14-114

28. Coppenrath V, Filosa LA, Akselrod E, Carey KM. Adaptation and Validation of the Fresno Test of Competence in Evidence-Based Medicine in Doctor of Pharmacy Students. Am J Pharm Educ [Internet]. 2017 Aug 1;81(6):106. Available from: http://www.ajpe.org/lookup/doi/10.5688/ajpe816106

\section{Publisher's Note}

Springer Nature remains neutral with regard to jurisdictional claims in published maps and institutional affiliations.

Ready to submit your research? Choose BMC and benefit from:

- fast, convenient online submission

- thorough peer review by experienced researchers in your field

- rapid publication on acceptance

- support for research data, including large and complex data types

- gold Open Access which fosters wider collaboration and increased citations

- maximum visibility for your research: over $100 \mathrm{M}$ website views per year

At BMC, research is always in progress.

Learn more biomedcentral.com/submissions 